\title{
Octylcyanoacrylate Skin Closure in Laparoscopy
}

\author{
Michael J. Sebesta, MD, Jay T. Bishoff, MD
}

\begin{abstract}
Objectives: Octylcyanoacrylate (Dermabond) is a dermal bond useful in closing surgical skin incisions. We compared skin octylcyanoacrylate with subcuticular skin sutures to close laparoscopic trocar sites.
\end{abstract}

Methods: A randomized, double-armed, prospective study was performed with 59 patients, in whom 228 trocar sites were closed. Twenty-nine patients underwent subcuticular closure of laparoscopic incisions, and 30 patients received closure with octylcyanoacrylate. Sutured trocar sites were closed with subcuticular 4-0 absorbable suture. Octylcyanoacrylate wounds received closure in accordance with the recommendations of the manufacturer (Ethicon, Somerville, NJ). The number of sutures or vials of octylcyanoacrylate used, closure times, and postoperative wound problems were recorded. Wounds were assessed 2 weeks postoperatively for healing complications. Closure costs were estimated using published operating room time per hour plus the cost of octylcyanoacrylate or suture. The Student paired $t$ test was used for statistical analysis.

Results: The overall mean time for skin closure using octylcyanoacrylate and suture was 3.7 minutes and 14 minutes, respectively $(P<0.00001)$. An average of 2.2 packets of suture were used to close all port sites, while those closed with octylcyanoacrylate required an average of 3.4 vials per patient. Wound complications consisted of subcuticular seroma with skin separation. No difference was noted in complication rates between the 2 groups. Overall average cost per closure using octylcyanoacrylate was $\$ 198$ while cost for closure using suture was $\$ 497(P<0.00001)$.

Conclusions: Laparoscopic port-site skin closure with octylcyanoacrylate is rapid and effective. Closure with octylcyanoacrylate yields cost savings and a decrease in

\footnotetext{
Wilford Hall Medical Center, Lackland AFB, Texas, USA (all authors).

Address reprint requests to: Jay T. Bishoff, MD, Department of Urology/MCSU, Wilford Hall Medical Center, 2200 Bergquist Dr, Ste 1, Lackland AFB, TX 78326, USA. Telephone: 210292 5755, Fax: 210292 7199, E-mail: Jay.Bishoff@Lackland.AF.mil

(C) 2004 by JSLS, Journal of the Society of Laparoendoscopic Surgeons. Published by the Society of Laparoendoscopic Surgeons, Inc.
}

operative time of more than 9 minutes per case.

Key Words: Laparoscopy, Skin closure, Octylcyanoacrylate.

\section{INTRODUCTION}

Traditionally, laparoscopic trocar sites have been closed using subcuticular sutures. Other closure methods include skin staples, full thickness cuticular sutures, surgical tape, and skin adhesives. Cyanoacrylates have been recognized for decades as excellent tissue adhesives. ${ }^{1}$ They are easy to use, cost-effective, and provide good cosmesis. ${ }^{2,3}$ Skin adhesives have been used extensively in the closure of pediatric extremity, head, and neck lacerations. Use of cyanoacrylates in otologic and ophthalmologic surgery has also been described. ${ }^{4,5}$

Octylcyanoacrylate (Dermabond, Ethicon; Somerville, $\mathrm{NJ}$ ) is a new generation, long- chain cyanoacrylate tissue adhesive. It is a combination of monomer and plasticizers that form a flexible bond but has a breaking strength comparable to 5-0 monofilament suture. Multiple clinical applications for which it is commonly being used exist. However, no studies compare its use in closing laparoscopic trocar sites.

The objective of this study was to determine the clinical applicability of octylcyanoacrylate in laparoscopic surgery for rapid closure of trocar sites compared with that in subcuticular suturing. We compared the speed, cost of closure, cosmetic result, and complications between these 2 closure methods.

\section{METHODS}

All patients undergoing laparoscopic surgery by one surgeon (JTB) were randomized to receive skin closure with either subcuticular suture or octylcyanoacrylate. Twentynine patients received subcuticular closure, and 30 patients received adhesive closure. In the suture group, 110 incisions were closed, and in the octylcyanoacrylate group, 118 incisions were closed. We recorded each patient's age, weight, type of surgery, preoperative 
antibiotics, blood loss, and intraoperative fluids (Tables 1 and 2). The time to close and dress the skin incisions was noted and recorded by the operating room nurse (Table 3). Patients were evaluated 2 weeks postoperatively for evidence of infection, dehiscence, seroma, and general cosmetic appearance. In addition, any complications associated with surgery were noted. In some patients undergoing nephrectomy, the kidney was extracted intact through an enlarged trocar site. The total length of trocar sites and extended incision was recorded for each patient.

The fascia of all sites $>1 \mathrm{~cm}$ were closed with absorbable suture. Wounds in both groups that did not closely approximate $1 \mathrm{~cm}$ received interrupted, subcutaneous sutures. The suture closure group received subcuticular closure with either 4-0 Vicryl or 4-0 Monocryl. Each wound was then dressed with steri-strips, a $2 \times 2-\mathrm{cm}$ gauze pad, and tape or a Tegaderm dressing. Octylcyanoacry-late adhesive was applied by approximation of the wound edges and topically painting the adhesive. Care was taken not to implant adhesive between the wound edges. No dressing was applied to the octylcyanoacrylate-closed wounds.

The closure times were compared for significance with the 2-tailed Student $t$ test. Closure costs were calculated using the sum of operating room time cost and cost of suture material or the octylcyanoacrylate. Operating room cost was estimated at $\$ 35$ per minute. ${ }^{6}$ The cost of 4-0 Vicryl was $\$ 3.60$ per packet, while 4-0 Monocryl was $\$ 4.12$ per packet. Dermabond (octylcyanoacrylate) costs $\$ 20.30$ per vial.

\section{RESULTS}

A total of 228 trocar sites were closed in 59 different patients. Twenty-nine patients received ocytlcyanoacrylate closure of 110 incisions. A mean of 3.8 incisions was made per patient (range, 3 to 6 ). The mean total length of incisions was $44.16 \mathrm{~mm}$ with a range from 25 to 95 $\mathrm{mm}$, and a standard deviation of $\pm 2.6 \mathrm{~cm}$. Mean closure time per case was 3 minutes 42 seconds (range, 2:41 to 5:00 minutes; standard deviation, $\pm 1: 13$ minutes).

The suture closure group consisted of 30 patients receiving closure of 118 incisions. A mean of 3.8 incisions was made per patient (range, 3 to 6 ). Mean total length of the incisions was $44 \mathrm{~mm}$ with a range of $20 \mathrm{~mm}$ to $115 \mathrm{~mm}$ and a standard deviation of $\pm 2.7 \mathrm{~cm}$. Mean closure time in this group was 14 minutes and 5 seconds (range, 8:27

\begin{tabular}{|c|c|c|}
\hline \multicolumn{3}{|c|}{$\begin{array}{c}\text { Table } \mathbf{1} . \\
\text { Operation Types }\end{array}$} \\
\hline$\overline{\text { Patient \# }}$ & Suture & Octylcyanoacrylate \\
\hline 1 & Nephrectomy & Pyeloplasty \\
\hline 2 & Nephrectomy & Partial nephrectomy \\
\hline 3 & Nephrectomy & Adrenalectomy \\
\hline 4 & Nephrectomy & Nephrectomy \\
\hline 5 & Partial nephrectomy & Heminephrectomy \\
\hline 6 & Partial nephrectomy & Nephrectomy \\
\hline 7 & Nephrectomy & Nephrectomy \\
\hline 8 & Lymph node biopsy & Nephrectomy \\
\hline 9 & Varicocelectomy & Nephrectomy \\
\hline 10 & Adrenal biopsy/MPLND & Nephrectomy \\
\hline 11 & Prostatectomy & Nephrectomy \\
\hline 12 & Partial nephrectomy & Nephrectomy \\
\hline 13 & Diverticulectomy & Prostatectomy \\
\hline 14 & Nephrectomy & Nephrectomy \\
\hline 15 & Nephrectomy & Nephrectomy \\
\hline 16 & Nephrectomy & Partial nephrectomy \\
\hline 17 & Pyeloplasty & Partial nephrectomy \\
\hline 18 & Nephrectomy & Nephrectomy \\
\hline 19 & Nephrectomy & Nephrectomy \\
\hline 20 & Nephrectomy & Nephrectomy \\
\hline 21 & Partial nephrectomy & Pyeloplasty \\
\hline 22 & Nephrectomy & Nephrectomy \\
\hline 23 & Pyeloplasty & Nephrectomy \\
\hline 24 & Nephrectomy & Adrenalectomy \\
\hline 25 & Partial nephrectomy & Nephroureterectomy \\
\hline 26 & Nephrectomy & Varicocelectomy \\
\hline 27 & Partial nephrectomy & Neprhrectomy \\
\hline 28 & Partial cystectomy & Herniorrhaphy \\
\hline 29 & Partial nephrectomy & Prostatectomy \\
\hline 30 & Nephrectomy & \\
\hline
\end{tabular}

to 24 :43 minutes; standard deviation, $\pm 6: 00$ minutes).

The mean octylcyanoacrylate cost per patient was $\$ 65.10$ (range, $\$ 40.60$ to $\$ 101.5$, standard deviation $\pm \$ 13.70$ ). Mean suture cost per patient was $\$ 7.74$ (range, $\$ 3.60$ to $\$ 10.80$; standard deviation, $\pm \$ 2.05$ ). Time cost in the ocytlcyanoacrylate group was a mean of $\$ 128.90$ (range, $\$ 69.60$ to $\$ 179.22$; standard deviation, $\$ 42.30$ ). The mean time cost for the suture group was $\$ 490.93$ (range, $\$ 295$ to $\$ 835$; standard deviation, $\$ 139.70$ ). Total cost in the groups was $\$ 193.32$ (range, $\$ 130$ to $\$ 365$; standard devi- 
JSLS

\begin{tabular}{|c|c|c|c|c|c|c|}
\hline \multicolumn{7}{|c|}{$\begin{array}{c}\text { Table } \mathbf{2 .} \\
\text { Operation Data }\end{array}$} \\
\hline Patient & \multicolumn{3}{|l|}{ Suture } & \multicolumn{3}{|c|}{ Octylcyanoacrylate } \\
\hline 1 & $163 / 82$ & 180 & $100 / 5900$ & $156 / 84$ & 180 & $300 / 2500$ \\
\hline 3 & $158 / 66$ & 230 & $1000 / 6000$ & $170 / 130$ & 145 & $50 / 2800$ \\
\hline 4 & $161 / 82$ & 150 & $200 / 2500$ & $163 / 71$ & 165 & $150 / 2100$ \\
\hline 5 & $166 / 80$ & 165 & $300 / 3000$ & $163 / 95$ & 180 & $200 / 3600$ \\
\hline 6 & $158 / 75$ & 240 & $600 / 4000$ & $163 / 75$ & 128 & $50 / 2500$ \\
\hline 7 & $154 / 50$ & 140 & $100 / 2000$ & $158 / 50$ & 150 & $100 / 6300$ \\
\hline 11 & $163 / 91$ & 300 & $200 / 3600$ & $158 / 82$ & 120 & $50 / 2500$ \\
\hline 12 & $173 / 95$ & 180 & $50 / 3000$ & $163 / 77$ & 180 & $50 / 3000$ \\
\hline 13 & $163 / 82$ & 180 & $150 / 3500$ & $158 / 75$ & 320 & $200 / 6000$ \\
\hline 14 & $168 / 86$ & 120 & $200 / 5600$ & $158 / 83$ & 180 & $300 / 3000$ \\
\hline 15 & $158 / 82$ & 180 & $100 / 6000$ & $168 / 95$ & 180 & $50 / 5400$ \\
\hline 16 & $173 / 136$ & 240 & $100 / 2800$ & $144 / 48$ & 120 & $50 / 2600$ \\
\hline 17 & $168 / 50$ & 180 & $50 / 4000$ & 163/82 & 140 & $100 / 2500$ \\
\hline 18 & $163 / 76$ & 128 & $50 / 2400$ & 158/82 & 110 & $50 / 2500$ \\
\hline 19 & $154 / 61$ & 194 & $120 / 4500$ & 163/82 & 120 & $50 / 2300$ \\
\hline 20 & 154/91 & 180 & $100 / 5800$ & $158 / 73$ & 120 & $150 / 2400$ \\
\hline 27 & $144 / 86$ & 210 & $150 / 2500$ & $158 / 82$ & 120 & $200 / 2700$ \\
\hline 28 & $168 / 86$ & 130 & $200 / 2800$ & 161/86 & 210 & $220 / 3200$ \\
\hline 29 & $163 / 86$ & 125 & $100 / 2000$ & 166/81 & 390 & $100 / 5500$ \\
\hline 30 & $158 / 64$ & 120 & $200 / 2500$ & - & - & - \\
\hline Mean & $145 / 81$ & 162 & $170 / 3510$ & $161 / 83$ & 159 & $113 / 3670$ \\
\hline
\end{tabular}

ation, \$49.40) for closure with octylcyanoacrylate, while suture closure cost a mean of $\$ 497$ (range, $\$ 295$ to $\$ 835$; standard deviation, \$139.70) $(P<0.0005)$.

Postoperative wound complications were similar for both groups. Five patients in the octylcyanoacrylate group had wound complications in 9 incisions. Two patients experienced skin separation in 5 incisions. One patient had a minor wound infection at one incision site treated with oral antibiotics. Two patients experienced small seromas at 3 incision sites, requiring incision opening and healing 
Table 3 .

Closure Times

\begin{tabular}{|c|c|c|c|c|c|c|}
\hline Patient & \multicolumn{3}{|l|}{ Suture } & \multicolumn{3}{|c|}{ Octylcyanoacrylate } \\
\hline 1 & 4 & 3 & 765 & 3 & 4 & 207 \\
\hline 2 & 5 & 3 & 885 & 3 & 4 & 218 \\
\hline 5 & 3 & 2 & 540 & 3 & 3 & 195 \\
\hline 6 & 4 & 1 & 761 & 4 & 4 & 310 \\
\hline 7 & 3 & 1 & 845 & 4 & 3 & 166 \\
\hline 8 & 3 & 2 & 720 & 2 & 3 & 161 \\
\hline 9 & 3 & 1 & 507 & 3 & 3 & 120 \\
\hline 10 & 6 & 3 & 1200 & 3 & 3 & 180 \\
\hline 15 & 4 & 2 & 607 & 4 & 4 & 288 \\
\hline 16 & 3 & 2 & 969 & 2 & 3 & 165 \\
\hline 17 & 3 & 1 & 933 & 2 & 4 & 165 \\
\hline 18 & 3 & 2 & 990 & 6 & 4 & 228 \\
\hline 19 & 3 & 2 & 896 & 3 & 3 & 126 \\
\hline 20 & 4 & 2 & 490 & 3 & 3 & 240 \\
\hline 21 & 4 & 2 & 810 & 3 & 3 & 160 \\
\hline 22 & 5 & 2 & 708 & 3 & 4 & 150 \\
\hline 23 & 4 & 2 & 720 & 4 & 3 & 216 \\
\hline 24 & 4 & 2 & 1260 & 4 & 4 & 490 \\
\hline 25 & 3 & 2 & 710 & 3 & 4 & 309 \\
\hline
\end{tabular}

by secondary intention. We noted small seromas in 2 patients receiving suture closure. These healed by secondary intention after skin opening and drainage. Table $\mathbf{4}$ presents a summary of the results.

\section{DISCUSSION}

The ultimate goal of surgical wound closure is to achieve a cosmetically acceptable, infection-free, and functional scar. Traditional methods of closing small trocar sites can be technically challenging, and time-consuming while adding to operating room costs. Simple skin reapproximation with a tissue adhesive provides a rapid, easy, and cost-effective alternative to traditional suture closure.

The use cyanoacrylates for tissue adhesion was first described in 1959. ${ }^{1}$ These liquid monomers polymerize in an exothermic reaction into a solid material upon contact with a fluid or basic material. Earlier use of shortchain cyanoacrylates demonstrated rapid degeneration 
Table 4.

Overall Results Summary

\begin{tabular}{lll}
\hline Mean Values & Octylcyanoacrylate & Suture \\
\hline No. of trocar sites & 3.8 & 3.8 \\
Total wound length & $44.16 \mathrm{~mm}$ & $44 \mathrm{~mm}$ \\
Closure time & $3: 42 \mathrm{~min}$ & $14.05 \mathrm{~min}$ \\
Material cost & $\$ 65.10$ & $\$ 7.74$ \\
Time cost & $\$ 128.90$ & $\$ 490.93$ \\
Total cost & $\$ 193.32$ & $\$ 497.00$ \\
\hline \hline
\end{tabular}

and inflammatory reactions. ${ }^{7}$ The longer chain derivative (octylcyanoacrylate) used today has not demonstrated these types of reactions. ${ }^{8}$ There exist numerous reports of success in using cyanoacrylates for closure of skin wounds without reports of toxicity or carcinogenicity.9-15

The application of octylcyanoacrylate to laparascopic surgical wounds provides an optimal closure method. In general, laparoscopic procedures are longer than are open surgical procedures. The longer operating room time adds to the procedure cost. Using octylcyanoacrylate is a closure method that decreases operating room time and overall procedure costs. In addition, the wounds in laparoscopy are small (generally less than 1 $\mathrm{cm}$ ). Lacerations less than $4 \mathrm{~cm}$ in length demonstrate comparable cosmetic results when closed with suture or octylcyanoacrylate. ${ }^{16}$ Consequently, laparoscopic surgical wounds are ideal for closure with a tissue adhesive. Wound closure with octylcyanoacrylate in laparoscopic procedures provides adequate closure with decreased operating room time and cost.

Our study demonstrates that the time for closure with octylcyanoacrylate is significantly decreased when compared with that for suture closure. The material costs of octylcyanoacrylate are higher than those for suture. Yet, when total closure costs (material expenses + operating room time) are considered, the octylcyanoacrylate closure is more economical than is suture closure. In addition, the quicker closure yields less anesthesia time and risk to the patient.

One consideration in closing deep abdominal wounds is the need for fascial reapproximation and deep subcutaneous sutures. This eliminates the subcutaneous dead space, decreases wound tension, and maximizes skin edge eversion. ${ }^{17}$ Thus, subcutaneous sutures should be placed in all deep and long $(>1 \mathrm{~cm})$ incisions. Because laparoscopic trocar sites are generally less than $1 \mathrm{~cm}$, only larger incisions from open trocar placement or tissue extraction benefit from approximation of deep tissue layers. Likewise, our closure times reflect the time necessary to apply adhesive to the skin. We do, however, recommend placement of deep sutures in longer incisions to provide optimal aesthetic closure.

Placement of the tissue adhesive is a simple procedure. It is, indeed, less technically demanding than placement of subcutaneous sutures. The surgeon must, however, avoid placing adhesive directly in the wound. This can be avoided by obtaining approximation with deep sutures. In addition, careful use of tissue forceps to obtain skin edge approximation and tissue eversion is effective. Any polymer deposited below the closure line will extrude through the wound, as would any foreign body. Our careful use the octylcyanoacrylate in skin closure resulted in the low wound complication rates.

Low wound complication rates may also be attributed to bacteriostatic properties of tissue adhesives. Both n-2butylcyanoacrylate and 2-octylcyanoacrylate demonstrate antimicrobial effects against gram-positive organisms.18 It has been demonstrated that wounds closed with n-2butylcyanoacrylate have considerable resistance to bacterial growth when compared with suture closure. ${ }^{19}$

\section{CONCLUSION}

The use of cyanoacrylate for skin closure in laparoscopic skin incisions is effective and economical. This method 
of skin closure has been proven to provide adequate cosmesis. It is much quicker to close these incisions with octylcyanoacrylate than suture. The technique for closure is easy to learn and not technically demanding. This leads to shorter overall operating times, lower cost, and greater efficiency in wound closure.

\section{References:}

1. Coover HN, Joyner FB, Sheerer NH, Wicker TH. Chemistry and performance of cyanoacrylate adhesive. Special Technical Papers. 1959;5:413-417.

2. Quinn JV, Drzewiecki AE, Li MM, et al. A randomized, controlled trial comparing a tissue adhesive with suturing in repair of pediatric facial lacerations. Ann Emerg Med. 1993;22:1130-1135.

3. Osmond $\mathrm{MH}$, Klassen TP, Quinn JV. Economic evaluation comparing a tissue adhesive with suturing in the repair of pediatric facial lacerations. J Pediatr. 1995;126:892-895.

4. Ronis ML, Harwick JD, Fung R, Dellavecchia M. Review of cyanoacrylate glues with emphasis on their otorhinolaryngologic applications. Laryngoscope. 1984;94:210-213.

5. Tse DT, Panje WR, Anderson RL. Cyanoacrylate adhesive used to stop CSF leaks during orbital surgery. Arch Ophthalmol. 1984;102:1337-1339.

6. Kohli N, Jacobs PA, Sze EHM, et al. Open compared with laparoscopic approach to Burch colposuspension: a cost analysis. Obst Gynecol. 1997;90:411-415.

7. Galil KA, Schofield ID, Wright GZ. Effect of n-2-butyl cyanoacrylate (histoacryl blue) on the healing of skin wounds. J Can Dent Assoc. 1984;50;565-569.

8. Ellis DAF, Shaikh A. The ideal tissue adhesive in facial plastic and reconstructive surgery. J Otolarygol. 1990;19:68-72.

9. Keng TM, Bucknall TE. A clinical trial of histoacryl in skin closure of groin wounds. Med J Malaysia. 1989;44:122-128.
10. Mizrahi S, Bickel A, Ben-Layish E. Use of tissue adhesives in the repair of lacerations in children. J Pediatr Surg. 1988;23:312313.

11. Applebaum JS, Zalut T, Applebaum D. The use of tissue adhesion for traumatic laceration repair in the emergency department. Ann Emerg Med. 1993;22:1190-1192.

12. Kamer FM, Joseph JH. Histoacryl: its use in aesthetic facial plastic surgery. Arch Otolaryngol Head Neck Surg. 1989;115:193197.

13. Halopuro S, Rintala A, Salo H, Ritsila V. Tissue adhesive versus sutures in closure of incision wounds. Ann Chir Gynaecol. 1976;65:308-312.

14. Morton RJ, Gibson MF, Sloan JP. The use of histoacryl tissue adhesive for the primary closure of scalp wounds. Arch Emerg Med. 1988;5:110-112.

15. Kung H. Evaluation of the Undesirable Side Effects of the Surgical Use of Histoacryl Glue With Special Regard to Possible Carcinogenicity. Basel, Switzerland: RCC Institute for Contract Research in Toxicology and Ecology; March 1986. Project 064315.

16. Quinn J, Wells G, Sutcliffe T, et al. A randomized trial comparing octylcyanoacrylate tissue adhesive and sutures in the management of lacerations. Ann Emerg Med. 1993;22:1130-1135.

17. Toriumi DM, O'Grady K, Desai D, Bagal A. Use of octyl-2cyanaoacrylate for skin closure in facial plastic surgery. Plastic Recon Surg. 1998;102:2209-2219.

18. Quinn JV, Osmond MH, Yurack JA, Moir PJ. N-2-butylcyanoacrylate: risk of bacterial contamination and its antimicrobial effects. J Emerg Med. 1995;13:581-585.

19. Noordzij JP, Foresman PA, Rodeheaver GT, Quinn JV, Edlich RF. Tissue adhesive wound repair revisited. I Emerg Med. 1994;12:645-649. 